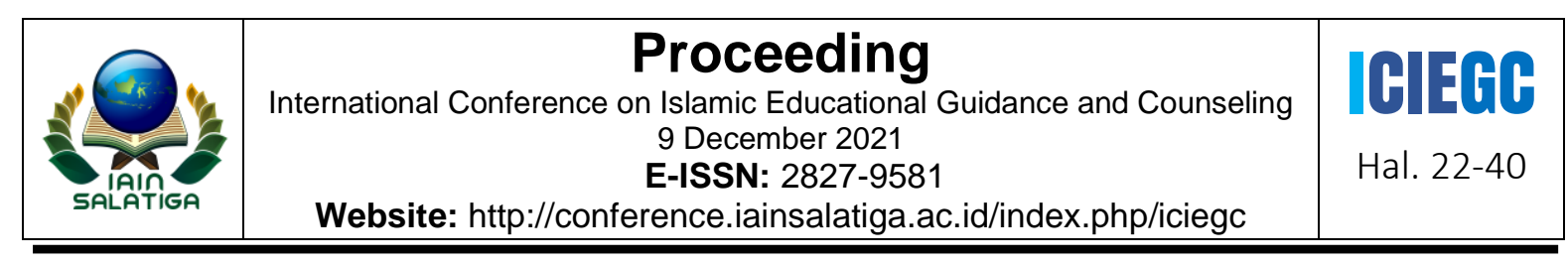

\title{
NILAI-NILAI KARAKTER DALAM KABA MINANGKABAU SABAI NAN ALUIH: KAJIAN HERMENEUTIKA
}

\author{
Syawaluddin' ${ }^{1}$ Andi Mappiare AT ${ }^{2}$, Adi Atmoko ${ }^{3}$, Nur Hidayah ${ }^{4}$, Amin Al Haadie Shafie ${ }^{5}$, \\ Nurfarida Deliani ${ }^{6}$ \\ 1,2,3,4 Universitas Negeri Malang \\ ${ }^{5}$ Universiti Sains Islam Malaysia \\ ${ }^{6}$ UIN Umam Bonjol Padang
}

\author{
Informasi Artikel \\ Penulis Korespondensi: \\ Syawaluddin, \\ Email: syawaluddin.1801119 \\ @ students.um.ac.id
}

\begin{abstract}
One of the developed values in empowering character education is Indonesia's cultural value. Indonesia surely has various cultures. One of them is Minangkabau's culture. For the Minangkabau community, $K a b a$ is a means to deliver advice, suggestions, and life teachings. One of Kaba Minangkabau realizations is Kaba Sabai Nan Aluih. This research applied a descriptive qualitative approach. The applied research type was Gadarmerian Hermeneutics. The data collection tools consisted of documentation and interview. The primary data source was from Kaba Minangkabau Sabai Nan Alluih. The applied data analysis was Part-Whole Gadarmerian Hermeneutics. Based on the Kaba Sabai Nan Aluih text review, two types of characters, positive and negative. The positive characters consisted of 16 characters while the negative characters consisted of 3 characters. The positive characters consisted of religiosity, responsibility, social awareness, wisdom, compassion, bravery, honesty, peace-loving, hardworking, independence, generosity, communication, compliance, patience, politeness, and empathy. The negative characters consisted of greed, arrogance, and ruthlessness. The obtained characters were expected to enrich and revitalize the cultural values within the character education.
\end{abstract}

Keyword: Character education; kaba sabai nan aluih 
Jawab, Peduli Sosial, Bijaksana, Kasih Sayang, Berani, Jujur, Cinta Damai, Kerja Keras, Mandiri, Dermawan, Komunikatif, Rela Berkorban, Sabar, Tegas dan Sopan. Sedangkan karakter negatif terdiri dari karakter Serakah, Sombong dan Kejam. Beragam Karakter yang sudah ditemukan dalam Kaba Sabai Nan Aluih diharapkan dapat memperkaya dan merevitalisasi nilai-nilai budaya dalam pendidikan karakter.

Kata kunci: Pendidikan Karakter; Kaba Sabai Nan Aluih

\section{PENDAHULUAN}

Salah-satu yang mendukung kemajuan suatu bangsa dan negara adalah karakter yang dimiliki oleh penduduknya. Pembangunan karakter bangsa Indonesia yang sudah dirintis sejak dahulu hingga sekarang kurang menampakkan hasil yang optimal. Hal ini terlihat masih marak terjadinya pelanggaran HAM, perampokan/korupsi, pergaulan muda-mudi yang melampaui batas (Setiawan, 2013), tawuran antar pelajar sampai memakan korban jiwa, bahkan pelajar tersebut membawa celurit dan gir (Kompas, 2020; Detik News, 2020; Oke News, 2020; CNN Indonesia, 2019; Basri, 2015), cyber bullying (CNN, 2015; Hukum Online.Com, 2019), oknum guru yang melakukan kekerasan terhadap siswa atau sebaliknya (Tribun News, 2019; Kompas, 2019 ).

Sikap santun yang biasanya digunakan masyarakat Indonesia dalam kehidupan bermasyarakat, berubah menjadi sikap kasar dan anarkis. Hal ini bisa dilihat pasca orde baru berakhir sampai kepada era reformasi, dimana masyarakat Indonesia mulai terpecah belah, saling caci maki di media social, bahkan survey yang dilakukan oleh LSM PIYS (Plan Indonesia dan Yayasan Sejiwa) di tahun 2008 di tiga Kota yaitu kota Surabaya, Yogyakarta serta Jakarta didapatkan hasil sebanyak $67 \%$ dari 1500an responden mendapatkan perundungan di sekolah. Dari hasil penelitian tersebut yang terlibat dalam tindakan perundungan tersebut adalah kawan/teman seangkatan, senior/kakak kelas, oknum pengajar/guru dan preman yang ada di sekitar lingkungan sekolah. Perundungan yang ditemukan berupa perundungan fisik seperti pukulan, tonjokan, tamparan, tendangan, pelecahan seksual seperti colekan, dicium paksa, hingga alat kelamin diraba. Sedangkan perundungan psikis seperti ejekan, hinaan, dipanggil dengan nama yang tidak sesuai dengan nama aslinya, dan lain sebagainya (Idrus, 2012).

Menurut Setiawan (2013) Berbagai peristiwa yang terjadi di atas tentu tidak sesuai dengan karakter bangsa Indonesia yang terkenal dengan kesantunan dan keramahannya. Selain itu, budaya tolong menolong, toleran terhadap perbedaaan yang ada, musyawarah dan mufakat dalam menyelesaikan suatu persoalan adalah karakter asli yang seharusnya 
dimiliki oleh Bangsa Indonesia. Namun fenomena di atas menandakan bahwa bangsa \& Negara Indonesia sedang ditimpa kritis moral, etika dan karakter bangsa (Idrus, 2012). Pembentukan karakter harus dimulai sejak dini, dan berkembang pada masa periode remaja. Fase remaja adalah fase kritis, karena remaja sedang masa proses pencarian jati diri. Pada fase ini individu mengalami perubahan signifikan, baik dalam hal fisik, psikis, emosi dan social (Batubara, 2010; David R. Shaffer \& Kipp, 2010; Hazen, Schlozman, \& Beresin, 2008; Lerner \& Laurence, 2004). Pada fase ini remaja semestinya sudah memiliki rencanarencana terkait tujuan-tujuan yang akan hendak dicapai dalam kehidupan individu, dan pada masa ini juga karakter individu terus berkembang, sehingga akan ditemukan sebagian remaja yang cenderung berprilaku menyimpang, seperti pelanggaran peraturan sekolah, perilaku membolos, dan lain sebagainya (Zen dalam Wardah, Hastuti, \& Krisnatuti, 2019). Pada masa ini dibutuhkan bimbingan dan penguatan karakter dari lingkungan sekitar, baik dari orangtua/keluarga, bimbingan guru di sekolah dan bimbingan dari lingkungan masyarakat.

Menurut Pradhan (2009) Karakter adalah elemen utama kepribadian manusia. Lickona (1991) menyatakan ada 3 bagian yang terdapat dalam karakter, yaitu pengetahuan moral, perasaan moral dan tindakan moral. Individu yang memiliki karakter akan tahu tentang kebaikan, menginginkan sesuatu yang baik dan melakukakan tindakan yang baik. Apabila individu terbiasa berpikir yang baik dan positif maka akan menimbulkan kebaikan dalam tindakan. Tiga hal tersebut dibutuhkan dalam membangun dan mengembangkan karakter pada individu. Tujuan dari pendidikan karakter adalah menjadikan siswa cerdas dan berperilaku baik. Saat anak/siswa hanya mendapatkan sedikit pendidikan moral di rumah, maka sekolah mempunyai peranan penting dalam membantu membentuk dan mengembangkan karakter pada diri anak.

Kebutuhan mendesak agar pendidikan karakter dilaksanakan adalah adanya gejalagejala yang mengindikasikan terkikisnya karakter bangsa. Menurut Lickona (1991) tandatanda hilangnya karakter bangsa adalah: a) Meningkatnya kekerasan di kalangan remaja (bahkan anak-anak). b) Meningkatnya budaya ketidakjujuran. c) fanatik yang berlebihan terhadap kelompok tertentu. d) Orang tua dan guru semakin tidak dihormati. e) Semakin kaburnya akhlak baik dan buruk. f) Menggunakan ucapan yang merendahkan (makian, hinaan, ejekan, hujatan, fitnah, menahan) tanpa memperhatikan perasaan orang lain. g) Meningkatnya perilaku merusak diri seperti penggunaan narkoba, alkohol, perjudian, dan 
seks bebas. H) Rendahnya rasa tanggung jawab sebagai individu dan warga negara. i) Menurunnya etos kerja dan saling curiga. j) semakin menurunnya kepedulian antar sesame.

Orangtua juga menginginkan anak mereka memiliki kemampuan dalam menilai yang baik \& benar, memiliki kepedulian mengenai hal yang baik \& benar dan melakukan tindakan yang baik \& benar, walaupun sedang berada dalam situasi yang tidak baik dan tidak benar. Pala (2011) menyatakan bahwa pembentukan dan peningkatan karakter harus diajarkan dari waktu kewaktu dan harus berkelanjutan.

Beberapa penelitian yang sudah dilakukan terkait dengan pendidikan karakter diantaranya adalah penelitian yang dilakukan oleh Hayati (2019) adapun hasil penelitiannya adalah model pendidikan karakter cerdas membantu individu aktif dalam melakukan aktivitas diskusi, selain itu model PKCKA membantu responden mengaitkan permasalahan karakter dengan buku saku yang dipakai dalam kegiatan tersebut. Kemudian penelitian yang dilakukan oleh Siswati, Utomo, \& Muntholib, (2018) adapun hasil penelitian menunjukkan bahwa pendidikan karakter tertanam dengan baik untuk membentuk sikap dan perilaku social peserta didik. Sedangkan penelitian lainnya menunjukkan bahwa implementasi pendidikan karakter bisa dilakukan dengan dua cara, yaitu strategi internal dan strategi eksternal. Starategi internal meliputi proses pembelajaran di kelas, aktivitas sehari hari dalam bentuk school culture, kegiatan pembiasaan dan kegiatan ekstrakurikuler. Sedangkan strategi eksternal adalah kerjasama pihak sekolah dengan orang tua dan masyarakat (Maunah, 2016).

Berbagai kiat yang sudah dilakukan untuk meningkatkan karakter individu sudah dilakukan oleh guru-guru ataupun peneliti yang berkecimpung dalam dunia pendidikan. Namun, berbagai penelitian yang dilakukan belum menggunakan pendekatan budaya dalam membangun karakter ideal individu. Menurut Sudrajat (2011) nilai budaya termasuk salah satu bagian yang terdapat dalam pengembangan pendidikan karakter di Indonesia. Tidak dapat dipungkiri, Indonesia terdiri dari beragam budaya. Menurut Miftah (2016) Keanekaragaman budaya yang ada di negara Indonesia adalah salah satu bentuk dan bukti di mana negara Indonesia kaya akan budaya. Hal ini juga didukung oleh Harahap \& Hasibuan, (2018) yang menyatakan bahwa Indonesia memiliki kekayaan budaya. Salah satunya yaitu budaya yang terdapat dalam masyarakat Minangkabau. Di Minangkabau dikenal istilah Adat Basandi Syara' (ABS); Syara' Basandi Kitabullah (SBK) \& Alam Takambang Manjadi Guru (Almos, Pramono, \& Reniwati, 2014; Piliang \& Sungut, 2018; Zubaidah, 2019) Ini berarti bahwa di Minangkabau semua aturan berdasarkan kepada Al- 
Qur'an dan Hadist. Nilai-nilai yang terdapat dalam falsafah ini selalu menjadi tuntunan bagi orang Minangkabau. Nilai-nilai yang terdapat dalam ABS dan SBK salah satunya diaplikasikan melalui Kaba Minangkabu. Kaba adalah cerita prosa berirama berbentuk narasi (kiasan) dan tergolong cerita panjang. Dari segi isi cerita, kaba ini sama dengan hikayat dalam sastra Indonesia lama atau novel dalam sastra Indonesia modern (Djamaris, 1992).

Banyak pesan atau nilai pendidikan karakter yang terkandung dalam sebuah kaba. Setiap kaba yang disampaikan terdapat tujuan yang ingin dicapai tukang kaba melalui ceritanya. Tujuan yang dimaksud adalah mendidik masyarakat melalui kaba atau cerita yang disampaikan si tukang kaba. Menurut salah seorang peneliti yang sebagian karya ilmiahnya menjadikan karya sastra Minangkabau sebagai objek kajian, kaba beramanat bahwa hidup yang ideal adalah hidup yang beriman, berilmu, berusaha dan bermanfaat bagi orang lain. Hidup yang tercela adalah hidup dengan senang-senang dan tidak bermanfaat dan bahkan menyusahkan orang lain (Abdurahman, 2011). Salah-satu bentuk Kaba Minangkabau adalah Kaba Sabai Nan Aluih. Kaba Sabai Nan Aluih adalah karya dari M. Rasyd Manggis Dt. R. Penghulu.

Kaba Sabai Nan Aluih bercerita tentang sosok perempuan yang berparas cantik, lemah lembut dalam bertutur dan santun saat bersikap. Di dalam teks kaba dikatakan bahwa sulit mencari perempuan yang bisa menandingi kecantikan Sabai Nan Aluih. Tokoh Sabai di dalam kaba Sabai Nan Aluih juga digambarkan sebagai anak yang berbakti, patuh, dan mendengarkan perkataan orangtua. Hal ini terlihat dalam kutipan teks berikut pada saat Sabai Nan Aluih dipanggil oleh Ibunya dan diberikan nasehat. Sabai selalu mendengarkan perkataan Ibunya dengan baik, tidak membantah, dan mengingatnya sampai kapanpun.

"Dangalah di anak mandeh, jikok urang naik ka ateh rumah, bia inyo rancak atau buruak, sambuiklah jo muko maniah, mintak duduak inyo dahulu, latakkan siriah ka dikunyah, latakkan ayia ka diminum, pinang kok alah digatoknyo, tanyo di anak baiak-baiak, apo ujuik jo sangajo, salasai barundiang sakiro-kiro, disinan baru anak lapeh, supayo sanang di hatinyo (Dengarlah di anak kandung, jika orang datang bertamu, biar ia tampan/cantik atau jelek, sambutlah dengan wajah manis, persilahkan ia duduk dulu, letakkan sirih untuk dikunyah, pinang jika sudaj diambilnya, baru Tanya baik-baik, apa maksud dan tujuannya). (KSNA, 2008:13)

Namun kecantikan Sabai Nan Aluih justru menjadi petaka. Hal ini berawal dari keinginan Rajo Nan Panjang ingin meminang anak gadis Rajo Babandiang yaitu Sabai Nan Aluih. Keinginan itu ditolak Rajo Babandiang, atas penolakan lamaran itu, Rajo Nan Panjang sangat marah kemudian mengajak Rajo Babandiang berkelahi. Dalam perkelahian 
tersebut Rajo Babandiang mati ditembak oleh anak buah Rajo Nan Panjang. Kematian Sabai menuntut balas dan Rajo Nan Panjang mati di tangan Sabai Nan Aluih.

Melalui Kaba Sabai Nan Aluih peneliti ingin menggali nilai-nilai pendidikan karakter apa saja yang terdapat dalam Kaba Sabai Nan Aluih. Nilai-nilai tersebut akan digali dari cerita dan bentuk-bentuk tuturan yang digunakan dalam Kaba Sabai Nan Aluih. Nilai-nilai karakter yang ditemukan dalam teks Kaba Sabai Nan Aluih diharapkan dapat memperkaya dan merevitalisasi nilai-nilai budaya dalam pendidikan karakter. Nilai pendidikan karakter diharapkan mampu menjadi kunci utama untuk menanamkan moralitas suatu kelompok atau golongan yang akan menjadi habit bagi setiap anggota kelompok di masyarakat.

\section{METODE}

Kajian ini merupakan penelitian kualitatif deskriptif. Adapun jenis penelitian dalam prosedur pengumpulan data, analisis data dan interpretasinya peneliti menggunakan strategi analisis hermeneutika Gadamerian. Penelitian ini nantinya memusatkan perhatian dalam pemaknaan suatu teks. Mappiare-AT (2013) menjelaskan bahwa sifat umum riset hermeneutika yaitu berupaya memahami, mendeskripsikan dan juga menginterpretasikan dunia realitas yang tersembunyi dalam suatu teks. Alat pengumpulan data menggunakan study dokumentasi dan wawancara. Sumber data primer berasal dari Kaba Minangkabau Sabai Nan Aluih karangan M. Rasyid Manggis Dt. R. Penghulu (Penghulu, 2008). Sumber data sekunder yaitu hasil wawancara langsung dengan ahli budaya Minangkabau. Analisis data yang dipakai dalam penelitian ini adalah analisis hermeneutika Gadamerian PartWhole. Pada proses interpretasi data hermeneutika terjadi interaksi antara penafsir (peneliti) dan teks yang akan ditafsirkan. Hal ini yang disebut oleh Gadamer sebagai proses dialogis, yakni suatu pandangan yang menekankan pada proses interaksi pembaca (peneliti) dengan teks.

Siklus part dan whole hermeneutic Gadameran yang digunakan sebagai berikut:

a) Penafsiran bagian-bagian, unsur atau bagian (part). Pada tahap ini peneliti membaca bagian-bagian kecil dari teks Kaba Sabai Nan Aluih (berupa kata, rangkaian kata, kalimat, rangkaian kalimat dan paragraf). Strategi penafsiran yang digunakan yaitu penerjemahan metafora. Strategi ini dipilih karena Kaba Sabai Nan Aluih tidak bisa diartikan secara langsung, namun perlu pemaknaan lebih lanjut karena Kaba Sabai Nan Aluih tersebut mengatakan sesuatu secara tidak langsung atau adanya ketidaksesuaian antara apa yang dikatakan dengan apa yang dimaksud (menggunakan kata-kata kiasan). 
b) Penafsiran secara keseluruhan (Whole). Pada tahap ini peneliti merangkai dan kemudian membingkai ulang bagian-bagian yang ada menjadi makna yang utuh. Dalam tahap ini peneliti melakukan dialog dengan memperhatikan prasangka pribadi (agama, latar belakang, gender, dan pribadi), meninjau dan menata kembali sambil memahami apa yang ada di dalam Kaba Sabai Nan Aluih tersampaikan kepada peneliti.

Memahami makna pokok (understanding of underlying meaning). Tahap ini peneliti melakukan dialog secara terus menerus. Ketika peneliti mencapai pemahaman makna pokok, maka penelitian dapat dinyatakan selesai (Mappiare-AT, 2013).

\section{HASIL DAN BAHASAN}

\section{Hasil Penelitian}

Pada bagian ini akan dijabarkan hasil kajian berdasarkan kajian teks yang sudah dilakukan. Bentuk-bentuk karakter yang ditemukan dalam Kaba Minangkabau Sabai Nan Aluih terdiri dari karakter positif dan karakter negative. Di bawah ini akan dijabarkan karakter positif yang terdapat dalam Kaba Sabai Nan Aluih sebagai berikut:

1. Karakter Religius

Karakter religius mencerminkan keberimanan terhadap Tuhan yang maha Esa. Hal ini tercermin melalui perilaku yang taat dalam melaksanakan ajaran yang dianut oleh individu, memiliki sifat tenggang rasa dan hidup rukun terhadap orang lain yang berbeda agama. Hal ini terdapat dalam teks Kaba Sabai Nan Aluih yang berbunyi:

Adok kapado alim ulama, suluah bendang dalam nagari, tampek batanyo saruweh tagah, tampek mangaji halal jo haram, nan mahukum sah jo batal (Hadap kepada Alim Ulama, suluh penerang dala nagari, tempat bertanya seruas larangan, tempat mengkaji halal dan haram, yang memutuskan sah dan batal) (KSNA, 2008:10)

Peran Alim Ulama amatlah penting dalam menjaga keamanan lingkungan baik itu lingkungan sosial, agama dan juga memutuskan suatu hal atau persoalan yang ada. Kehadirannya membawa kedamaian dan penyelesaian atas masalah yang ada, sehingga tercipta suasana yang damai. Menurut Zainuddin (2014) dalam kehidupan masyarakat Minangkabau dikenal istilah Adat Basandi Syara' (ABS) dan Syara' Basandi Kitabullah (SBK). Hal ini dapat dimaknai bahwa tingkah laku orang Minangkabau berlandaskan kepada Al-Qur'an dan Hadist. Artinya tingkah laku dalam menghormati dan menghargai setiap perbedaan yang ada sejak dini sudah diajarkan pada masyarakat Minangkabau. Nilainilai religius yang diajarkan dalam agama merupakan sebuah acuan utama yang membawa individu untuk membentuk dan mengembangkan kehidupan yang berkarakter. Di dalam Kaba Sabai Nan Aluih terdapat 1 teks yang menceritakan tentang karakter Religius. 
2. Karakter Tanggung Jawab

Karakter tanggung jawab yaitu pola pikir, sikap dan perbuatan individu terhadap hak dan kewajiban yang harus dikerjakan dan diselesaikan oleh individu, dan hal tersebut memberikan dampak positif terhadap dirinya dan lingkungan sekitarnya. Dalam masyarakat Minangkabau bertanggung jawab terhadap diri sendiri dan orang lain sudah diajarkan sedari dini kepada individu. Hal ini terdapat dalam teks Kaba Sabai Nan Aluih yang berbunyi

Niniak Mamak di Padang Tarok, kayu rindang di tangah koto, ureknyo tampek baselo. Batangnya tampek basanda, daunnya perak jo suaso, bungonyo ambiak ka suntiang, buahnya buliah di makan, tampek bataduah katiko hujan, tampek balinduang di hari paneh (Ninik Mamak di Padang Tarok kayu rindang di tengah masyarakat, uratnya tempat bersila, batangnya tempat bersandar, daunnya perak dan suasa, bunganya ambil untuk sunting, buahnya boleh dimakan, tempat berteduh ketika hujan, tempat berlindung di hari panas) (KSNA, 2008:9)

Niniak mamak mempunyai kedudukan yang lebih tinggi dibanding jabatan lainnya yang ada dalam masyarakat, niniak mamak merupakan tempat sandaran dan tempat bertanya tentang berbagai permasalahan yang di hadapi warga dalam suatu nagari. Perilaku di atas merupakan perwujudan dari tanggung jawab dari seorang niniak mamak dalam suatu nagari/kampung. Di dalam Kaba Sabai Nan Aluih terdapat 1 teks yang menceritakan tentang karakter tanggung jawab.

\section{Karakter Peduli Sosial}

Peduli sosial adalah karakter yang berkaitan dengan pikiran, sikap dan perbuatan pada individu yang suka memberikan bantuan terhadap orang lain tanpa melihat status social orang tersebut. Dalam masyarakat Minangkabau diajarkan agar peduli terhadap lingkungan social dan tolong menolong dalam segala hal yang positif. Karakter peduli sosial tertuang dalam Teks Kaba Sabai Nan Aluih yang berbunyi:

Lalu mahimbau anak gubalo "Aciak oi Sabai Nan Aluih, manga aciak batanun juo, Bapak Aciak Garanlah mati, ditembak Rajo Nan Panjang, ditengah padang pahaunan, baliau kinitaguliang surang, di munggu kacenaian, dibawah cubadak condong (Kakak Sabai Nan Aluih, kenapa kakak masih bertenun, bapak kakak gerangan sudah mati, ditembak Rajo Nan Panjang, di tengah padang pahaunan,beliau sekarang terguling sendiri, di munggu yang tampak jelas, di bawah nangka yang condong) (KSNA, 2008:48-49).

Teks Kaba di atas menceritakan tentang Sikap anak gembala yang berusaha keras untuk bisa sampai di rumah Sabai, agar dapat menyampaikan berita duka atau bencana yang menimpa keluarga Sabai karena terbunuhnya ayahanda Sabai. Teks di atas merupakan 
perwujudan karakter peduli social. Di dalam Kaba Sabai Nan Aluih terdapat 2 teks yang menceritakan tentang karakter peduli social.

4. Karakter Bijaksana

Kebijaksanaan adalah kepandaian menggunakan akal budinya (pengalaman dan pengetahuannya); Kecakapan bertindak apabila menghadapi kesulitan. Dari pengertian tersebut kebijaksanaan dapat dimaknai sebagai suatu kecakapan atau ketrampilan dalam menghadapi setiap peristiwa kehidupan secara cerdas. Karakter kebijaksanaan tertuang dalam Teks Kaba Sabai Nan Aluih yang berbunyi:

Mandang nasehat bapak kanduang, tunduak tapakua hanyo lai, dek anak saparentah bapak, panek bana batikam lidah, di bapak juo nan ka lalu, sabai nan tahu di bapaknyo, lunaknyo indak tasudu, karehnyo indak tatakiak, bukan bak lantah di tangah bancah, bukan condong Kamari rabah (Mendengar nasehat Ayah Kandung, Sabai tunduk terdiam, karena anak seperintah ayah, percuma saja adu pendapat, karena tidak sependapat, pendapat ayah juga yang dijalankan, Sabai yang tahu dengan karakter ayahnya " lunaknya tidak tersudu, kerasnya tidak tergores, bukan seperti lumpur di tengah sawah, bukan condong kemari rebah) (KSNA, 2008:31)

Teks kaba di atas bercerita tentang kebijaksanaan Sabai Nan Aluih saat berbicara dengan ayahnya, dimana Sabai melarang ayahnya untuk pergi ke pekan besok hari. Namun Raja Babandiang sudah berjanji akan menemui Raja Nan Panjang dan tidak akan mungkin ia mengingkari janjinya. Melihat hal tersebut Sabai hanya tertunduk dan berusaha memahami, karena ia tahu meski Raja Babandiang seorang ayah yang lembut dan penyayang, disisi lain ayahnya adalah seorang yang memegang keras dan memegang prinsip kehidupan. Di dalam Kaba Sabai Nan Aluih terdapat 7 teks yang menceritakan tentang karakter kebijaksanaan.

\section{Karakter Kasih Sayang}

Kasih sayang adalah wujud perhatian dan kepedulian seseorang terhadap orang lain yang diwujudkan dengan pengorbanan seseorang. Karakter kebijaksanaan tertuang dalam Teks Kaba Sabai Nan Aluih yang berbunyi:

Dek sayang pado Sabai Nan Aluih, kasiah sapanjang ayia hilia, dibujuk malah anak kanduang (Karena sayang kepada Sabai Nan Aluih, kasih sepanjang air mengalir, dan dibujuklah anak kandung) (KSNA, 2008:29)

Teks kaba di atas bercerita tentang saat Raja Babanding melihat Sabai Nan Aluih bermenung di Rumah Gadang. Raja Babandiang menanyakan kepada Sabai kenapa bermenung dan ia berusaha menghibur Sabai agar jangan bersedih. Kaba ini merupakan 
wujud kasih sayang Raja Babandiang kepada anaknya Sabai Nan Aluih. Di dalam Kaba Sabai Nan Aluih terdapat 4 teks yang menceritakan tentang karakter kasih sayang.

6. Karakter Berani

Keberanian diartikan sebagai sifat yang berani menanggung resiko dalam pembuatan keputusan dengan cepat dan tepat waktu. Sifat keberanian seseorang tidak dimiliki sejak lahir tetapi sifat ini dapat dibentuk dengan membuat suasana yang kondusif sehingga dia merasa nyaman dan lebih percaya diri. Karakter keberanian tertuang dalam Teks Kaba Sabai Nan Aluih yang berbunyi:

Lapeh nan dari pintu kaporo, bajalan panjang hanyo lai, takajuak urang di kampuang, tacangang urang nan banyak, maliek Sabai Nan Aluih, turun rumah baru sakali nangko (Setelah keluar rumah, menuju tempat yang belum jelas, terkejut orang di kampung, tercegang orang banyak, melihat penampilan Sabai Nan Aluih sekali ini) (KSNA, 2008:52)

Teks Kaba di atas bercerita tentang keberaniaan Sabai Nan Aluih saat memutuskan pergi ke Padang Pahaunan menjemput jenazah ayahnya yang dibunuh oleh Raja Nan Panjang. Orang kampung banyak yang terkejut melihat keberaniannya, kerena Sabai sebelumnya anak gadis yang tidak pernah keluar rumah. Di dalam Kaba Sabai Nan Aluih terdapat 13 teks yang menceritakan tentang karakter berani.

7. Karakter Jujur

Jujur merupakan sebuah sifat yang membutuhkan kesesuaian sikap antara perkataan yang diucapkan dan perbuatan yang dilakukan oleh seseorang. Artinya, seseorang dapat dikatakan jujur jika ia mengucapkan sesuatu yang sesuai dengan sebenarnya, disertai tindakan yang seharusnya. Karakter jujur tertuang dalam Teks Kaba Sabai Nan Aluih yang berbunyi:

Rajo Babandiang urang basa, indak tahu titian lapuak, indak pandai bajanjia mungkia, janji salalu ditepati, ikara selalu dimuliakannyo (Raja Babandiang orang besar, tidak tahu dengan titian lapuk, tidak pandai ingkar janji, janji selalu ditepati, ikrar selalu dimulikan) (KSNA, 2008:38).

Teks di atas bercerita tentang Raja Babandiang adalah orang yang jujur dan selalu menepati janjinya. Apabila janji sudah diucapkannya, maka pantang Raja Babandiang akan mengingkarinya. Di dalam Kaba Sabai Nan Aluih terdapat 4 teks yang menceritakan tentang karakter jujur. 


\section{Karakter Cinta Damai}

Karakter cinta damai adalah pola pikir, sikap dan tindakan yang senantiasa memberikan kedamaian dan rasa aman terhadap orang lain. Karakter cinta damai tertuang dalam Teks Kaba Sabai Nan Aluih yang berbunyi:

Namonyo kito basahabat, eloklah duduak sakutiko, mangunyah siriah sakapua surang, Manolah Tuanku Rajo Nan Panjang, Siriah Nan Lah Tuanku Kunyah, Pahik Manihnyo Lah Diraso, Sananglah Hati Mandangakan (Namanya kita bersahabat, baiknya kita duduk sebentar sambil mengunyah sirih, "manalah Tuanku Raja Nan Panjang, sirih yang tuan kunyah, pahit manisnya sudah dirasa, senang juga saya mendengarnya) (KSNA, 2008:40-41).

Teks di atas bercerita tentang karakter cinta damai yang dimiliki oleh Raja Babandiang, baginya Raja Nan Panjang adalah sahabat lamanya. Sebelum perkelahian antara Raja Babandiang dan Raja Nan Panjang terjadi, ia masih memberikan pemahaman kepada Raja Nan Panjang, bahwa Sabai Nan Aluih belum mau berumah tangga. Selain itu, Raja Nan Panjang adalah seorang yang sudah tua, tentunya tidak akan sesuai dengan Sabai yang seumuran cucunya Raja Nan Panjang. Di dalam Kaba Sabai Nan Aluih terdapat 1 teks yang menceritakan tentang karakter cinta damai.

\section{Karakter Kerja Keras}

Karakter kerja keras merupakan perilaku individu bersungguh-sungguh dalam mengatasi setiap hambatan dalam mencari ilmu ataupun menyelesaikan tugas-tugasnya. Karakter kerja keras tertuang dalam Teks Kaba Sabai Nan Aluih yang berbunyi:

"Birawari Rajo Babandiang, duo panggalah matohari naiak, jalan batambah jauah juo, lah sarantang pajalan, lah duo rantang pajalanan, cukuik katigo rantang panjang, kok jauah hampia ka sampai, kok sampai tibolah kini, lah tibo garan di sinan, iyo di padang pahaunan, di munggu nan kecenaian (Adapun Raja Babandiang, dua galah matahari naik, jalan bertambah jauh juga, sudah serentang perjalanan, sudah dua rentang perjalanan, cukup ketiga rentang panjang, jika jauh hampir sampai, jika sampai tibalah sekarang, sudah sampai gerangan di sana, di padang Pahaunan, di munggu yang tampak jelas) (KSNA, 2008, 39)

Teks di atas bercerita tentang usaha dan kerja keras Rajo Babandiang demi menepati janjinya untuk bertemu Rajo Nan Panjang di Padang Pahaunan, meski panas matahari yang harus dihadang dan jauh perjalanan yang harus ditempuh. Hal itu sesuai dengan karakter kerja keras yang menunjukkan upaya sungguh-sungguh dalam mengatasi berbagai hambatan belajar dan tugas, serta menyelesaikan tugas dengan sebaik-baiknya. Di dalam Kaba Sabai Nan Aluih terdapat 1 teks yang menceritakan tentang karakter kerja keras. 


\section{Karakter Mandiri}

Karakter mandiri adalah pola pikir, sikap dan tindakan yang mandiri/tidak tergantung kepada orang lain. Karakter mandiri tertuang dalam Teks Kaba Sabai Nan Aluih yang berbunyi:

Lah tagak Sabai Nan Aluih, taruihnyo masuak ka biliak dalam, diambiak badia salareh, sarato masiu dalam tompang, dikanakkan pakaian sagalo hitam, bakodek sarawa dalam, kain kapalo kipeh takambang, cawek salendang tanah liyek, tajumbai hinggi lutuik kida, di pasisik karih sabilah, badukuah baantiang-antiang, bagalang ciek sabalah, sambilan cincin di jari, cincin banamo kasadonyo (Sudah berdiri Sabai Nan Aluih, terus dia masuk ke bilik dalam, diambil bedil sebuah, serta mesiu dalam tompang, dikenakkan pakaian serba hitam, berkodek celana dalam, kain kepala kipas terkembang, cawat selendang tanah liat, terjumbai hingga lutut kiri, disisipkan keris sebilah, berkalung beranting-anting, bergelang satu sebelah, sembilan cincin di jari, cinci bernama semuanya) (KSNA, 2008:51)

Pada kutipan tersebut dapat diketahui bahwa Sabai telah mampu mengatasi masalahnya sendiri atau mampu mengambil keputusan dan sikapnya yang langsung bersiapsiap untuk menjemput ayahnya yang dikabarkan telah dibunuh oleh Rajo Nan Panjang. Teks di atas menggambarkan karakter mandiri yang dimiliki oleh Sabai Nan Aluih. Di dalam Kaba Sabai Nan Aluih terdapat 3 teks yang menceritakan tentang karakter mandiri.

\section{Karakter Dermawan}

Kedermawanan adalah kebaikan hati terhadap orang lain, kemurahan hati. Kedermawanan berasal dari kata dermawan yang artinya adalah orang yang suka memberikan derma atau pemurah hati. Kedermawanan merupakan sifat terpuji dengan memberikan harta kepada orang lain tanpa diminta haknya. Karakter dermawan tertuang dalam Teks Kaba Sabai Nan Aluih yang berbunyi:

Birawari Sadun Saribai, limpapeh rumah nan gadang, amban paruak aluang bunian, urang kayo suko dimakan, ganti suri tuladan kain, tampek batanyo dek rang kampuang, tampek si miskin salang tenggang (Mengenai Sadun Saribai, perempuan berhati mulia, pengatur harta pusaka, orang kaya yang dermawan, menjadi suri tauladan, tempat bertanya bagi orang kampung, tempat si miskin beselang tenggang) (KSNA, 2008:11)

Teks di atas berceriita tentang Sadun Saribai Ibunya dari Sabai Nan Aluih adalah seorang wanita yang dermawan. Sadun Saribai adalah perempuan yang begitu dihormati, memiliki sifat dermawan dan tauladan bagi orang kampung. Di dalam Kaba Sabai Nan Aluih terdapat 1 teks yang menceritakan tentang karakter dermawan. 


\section{Karakter Komunikatif}

Karakter komunikatif adalah pola pikir, sikap dan tindakan yang senang bergaul, bekerja sama dan berkomunikasi dengan orang lain. Karakter komunikatif tertuang dalam Teks Kaba Sabai Nan Aluih yang berbunyi:

Anak Kanduang Sabai Nan Aluih, pamenan mato patang pagi, ubek jariah palarai damam, pincuran darah di kaniang, sibiran tulang nan suok, ka mari malah duduak, ado nan ka mandeh katokan (Anak Kandungku Sabai Nan Aluih, pandangan mata sore pagi, obat lelah dan deman, kesinilah nak, ada yang mau ibu sampaikan) (KSNA, 2008:12)

Teks di atas bercerita tentang Sadun Saribai Ibunya Sabai Nan Aluih Dengan Penuh Kelembutan Mengajak Sabai untuk berbicara. Teks di atas menggambarkan karakter komunikatif yang dimiliki oleh ibunya Sabai Nan Aluih. Di dalam Kaba Sabai Nan Aluih terdapat 1 teks yang menceritakan tentang karakter komunikatif.

\section{Karakter Rela Berkorban}

Rela berkorban merupakan bersedia dengan ikhlas, senang hati, dengan tidak mengharapkan imbalan, dan mau memberikan sebagian yang dimiliki sekalipun penderitaan bagi dirinya sendiri. Karakter rela berkorban tertuang dalam teks Kaba Sabai Nan Aluih yang berbunyi:

Dangalah di anak mandeh, jikok urang naik ka ateh rumah, bia inyo rancak atau buruak, sambuiklah jo muko maniah, mintak duduak inyo dahulu, latakkan siriah ka dikunyah, latakkan ayia ka diminum, pinang kok alah digatoknyo, tanyo di anak baiak-baiak, apo ujuik jo sangajo, salasai barundiang sakiro-kiro, disinan baru anak lapeh, supayo sanang di hatinyo (Dengarlah di anak kandung, jika orang datang bertamu, biar ia tampan/cantik atau jelek, sambutlah dengan wajah manis, persilahkan ia duduk dulu, letakkan sirih untuk dikunyah, pinang jika sudah diambilnya, baru tanya baik-baik, apa maksud dan tujuannya). (KSNA, 2008:13)

Teks di atas bercerita tentang Sadun Saribai yang mengajarkan kepada Sabai untuk menghormati tamu dan tidak memandang tamu tersebut dari segi fisik maupun harta. Saat ada orang bertamu, maka yang punya rumah harus melayani dengan baik. Teks di atas menggambarkan karakter rela berkorban. Di dalam Kaba Sabai Nan Aluih terdapat 3 teks yang menceritakan tentang karakter rela berkorban.

\section{Karakter Sabar}

Sabar adalahsuatu sikap menahan emosi dan keinginan, serta bertahan dalam situasi sulit dengan tidak mengeluh. Sabar merupakan kemampuan mengendalikan diri yang juga dipandang sebagai sikap yang mempunyai nilai tinggi dan mencerminkan kekokohan jiwa orang yang memilikinya. Karakter sabar tertuang dalam teks Kaba Sabai Nan Aluih yang berbunyi: 
Banduanglah tangih dalam rumah, Sabai baduo jo mandeh kanduangnyo, indak sia kamaantokkan, adok kapado Sadun Saribai, sungguhpun ramuak dalam hati, dimuko indak kalihatan, junjuangan garanlah pai, lah langang rumah nan gadang, pai kasia tampek batanyo, pulang kasia babarito (Menangislah mereka dalam rumah, Sabai berdua dengan ibunya, tidak tahu siapa yang akan mendiamkan, akan tetapi Sadun Saribai meskipun hatinya remuk, di wajahnya tidak dinampakkan, suaminya sudah meninggal, akan sepi rumah Gadang, tidak akan ada lagi tempat bertanya saat pergi dan tempat berberita saat pulang) (KSNA, 2008:35)

Teks di atas bercerita tentang kesabaran yang dimiliki Sabai dan ibunya. Saat mereka mendengar berita dari anak gembala bahwa Raja Babandiang ditembak Raja Nan Panjang maka pecahlah tangis Sadun Saribai dan Sabai Nan Aluih. Nmaun, Sadun Saribai meskipun hatinya remuk, ia tetap berusaha menenangkan Sabai Nan Aluih. Perilaku di atas menggambarkan tentang kesabaran yang dimiliki oleh Sabai Nan Aluih dan ibunya. Di dalam Kaba Sabai Nan Aluih terdapat 3 teks yang menceritakan tentang karakter sabar.

\section{Karakter Tegas}

Tegas adalah sikap yang berani dan percaya diri mengungkapkan apa yang benar dan yang salah, apa yang diinginkan dan tidak diinginkan secara jelas, nyata dan pasti. Karakter tegas tertuang dalam teks Kaba Sabai Nan Aluih yang berbunyi:

Iyo bana waang mangkutak, sarupo indak batunjuk $i$, kok kalua urang di musajaik, banampak waang ba alang-alang, bapak juo nan kanai malu, sabagai pulo adiak kanduang, sapaneh ikolah hari, kok tumbuah sakik ngilu paniang, adiak juo nan kamaidokkan (Iya kamu mangkutak, seperti tidak diajari, jika orang keluar dari Masjid, dan engkau bermain layang-layang, Ayah juga yang akan malu, sepanas ini hari, jika engkau sakit, engkau juga yang akan merasakan) (KSNA, 2008:17)

Teks di atas menceritakan tentang Sabai Nan Aluih yang mengingatkan Mangkutak Alam yang akan bermain layang-layang di tengah teriknya matahari. Sabai Nan Aluih tidak mengizinkan adiknya untuk pergi bermain, karena pada jam itu juga orang-orang sedang melaksanakan Sholat di Masjid. Jika orang melihat adiknya bermain layang-layang maka ayahnya juga yang akan menanggung malu. Perilaku di atas menggambarkan tentang karakter ketegasan. Di dalam Kaba Sabai Nan Aluih terdapat 4 teks yang menceritakan tentang karakter ketegasan.

\section{Karakter Sopan}

Sopan adalah sikap hormat dan beradap dalam perilaku, santun dalam tutur kata, budi bahasa dan kelakuan yang baik sesuai dengan adat istiadat dan budaya setempat yang harus kita lakukan. Karakter sopan tertuang dalam Teks Kaba Sabai Nan Aluih yang berbunyi:

Alah duduak Sabai Nan Aluih, duduk basimpuah di muko mandeh (Sudah duduk Sabai Nan Aluih, duduk bersimpuh di depan ibu) (KSNA, 2008:12) 
Teks di atas menceritakan tentang karakter sopan yang dimiliki oleh Sabai Nan Aluih. Saat Sabai dipanggil ibunya, ia menyahuti dan duduk bersimpuh di depan ibunya. Di dalam Kaba Sabai Nan Aluih terdapat 1 teks yang menceritakan tentang karakter sopan.

Selanjutnya akan dijabarkan karakter-karakter negatif yang terdapat dalam Kaba Sabai Nan Aluih sebagai berikut:

\section{Serakah}

Serakah atau tamak yaitu sikap tidak puas dengan yang menjadi hak atau miliknya, sehingga berupaya untuk meraih yang bukan haknya tanpa menghiraukan cara halal atau haram. Karakter serakah tertuang dalam teks Kaba Sabai Nan Aluih yang berbunyi:

Manolah Tuanku Rajo Babandiang, siriah tuanku lah ambo kunyah, alah taraso manih pahiknyo, maniahnyo hinggo ujuang lidah, pahiknyo tingga di rakuangan, nan sekarang kini nangko, taadok rundingan nan bamulo, tampuang inyo indak hanyuik, tarandam inyo indak basah, ambo digantuang indak Batali (Manalah Tuanku Raja Babandiang, sirih sudah saya kunyah, sudah terasa manis dan pahitnya, manisnya hingga ujung lidah, pahitnya tinggal di kerongkongan dan sekarang terkait rundingan kita yang dahulu, tertampung tidak hanyut, terendam tidak basah, saya digantung tidak bertali) (KSNA, 2008:41)

Teks di atas menceritakan tentang Raja Nan Panjang yang menuntut Raja Babandiang Tagak karena tidak menerima lamarannya. Raja Nan Panjang merasa ia adalah Raja yang sangat kaya dan tidak ada alasan untuk menolak lamarannya. Ia merasa terhina saat Raja Babandiang menolak lamarannya kepada Sabai Nan Aluih. Di dalam Kaba Sabai Nan Aluih terdapat 5 teks yang menceritakan tentang karakter serakah.

2. Sombong

Sombong (takabur) adalah merasa bangga pada diri sendiri, merasa paling baik atau paling hebat dan merasa paling benar sehingga menolak kebenaran dan merendahkan orang lain. Karakter sombong tertuang dalam Teks Kaba Sabai Nan Aluih yang berbunyi:

Apo nan kurang pado denai, kok sawah bajanjang-janjang, rangkiang ranjuang lumbuangpun bapereang, Sanan Bakato hanyo lai, Si Sabai parmato taruhan tuan, nak ambo ikek jo ameh mutu, tapi... Tuan tulak batarang-tarang (Apa yang kurang pada diri saya, sawah saya berjenjang-jenjang, rangkiang saya penuh dengan isinya, si Sabai anak tuan ingin saya jadikan istri, tapi tuan menolak terang-terang) (KSNA, 2008:42)

Teks di atas menceritakan tentang karakter sombong yang dimiliki Raja Nan Panjang. Dengan omongannya yang meninggi Raja Nan Panjang mengatakan kepada Raja Babandiang Tagak bahwa tidak alasan apapun untuk menolak lamarannya, ia punya sawah yang luas, hasil panen yang banyak, ia raja yang kaya. Namun, Raja Babandiang Tagak 
terang-terangan menolak lamarannnya. Di dalam Kaba Sabai Nan Aluih terdapat 5 teks yang menceritakan tentang sifat sombong.

3. Kejam

Kejam dalam KBBI berarti tidak menaruh belas kasihan; bengis; zalim. Karakter kejam tertuang dalam Teks Kaba Sabai Nan Aluih yang berbunyi:

Adiak denai Sabai Nan Aluih, bukannyo salah dari denai, salah di Bapak Adiak juo, saelok itu denai datang, diantakan siriah dangan pinang, kok adat nan denai isi, limbago nan denai tuang, manuruik langgam Padang Tarok, tapi rupunyo di bapak adiak, adok siriah nan lah datang, tampuiknyo indak digutiah, ujuangnyo indak dicabiak, lai koh rajo maulak sambah,? denai bakandak indak dibari, denai mambali indak manjua, nan sakarang kini nangko, talampau indak dapeh dipinteh, tasorong indak dapek dibubuik, suratan alah dahulu (Adiak Sabai Nan Aluih, bukannya salah saya, salah ayahmu juga, sebaik itu saya danang, saya hantarkan sirih dengan pinang, adat sudah saya isi, limbago sudah saya tuang, menurut ke Padang Tarok, tapi ayahmu tidak merespon dengan baik, sirih yang sudah dihantar tidak diambil, padahal yang datang meminang adalah raja, saya ingin tapi tidak diberi, saya ingin membeli tapi tidak dijual, sekarang begini saja, karena hendak tidak tercapai, dan ayahmu meninggal adalah suratan) (KSNA, 2008:60)

Teks di atas menceritakan tentang sifat kejam yang dimiliki Raja Nan Panjang. Raja Nan Panjang mengatakan kepada Sabai Nan Aluih bahwa Raja Babandiang Tagak tewas karena ulah Raja Babandiang Tagak sendiri. Raja Nan Panjang tidak terima dan murka karena ayah Sabai Nan Aluih menolak lamarannya dan ini pantangan bagi Raja Nan Panjang. Bagi Raja Nan Panjang apapun keinginannya harus terwujud dan tidak seorangpun boleh menolak apa yang ia inginkan. Di dalam Kaba Sabai Nan Aluih terdapat 5 teks yang menceritakan tentang sifat kejam.

\section{Pembahasan}

Kaba Sabai Nan Aluih adalah salah satu karya sastra Minangkabau yang cukup dikenal oleh masyarakatnya. Kaba Sabai Nan Aluih karya M. Rasyid Manggis merupakan karya sastra yang berlatarkan Minangkabau. Tokoh-tokoh utamanya adalah Raja Babandiang Tagak (ayahnya Sabai Nan Aluih), Sadun Saribai (Ibunda Sabai Nan Aluih), Sabai Nan Aluih, Mangkutak Alam (adik Sabai Nan Aluih) dan Raja Nan Panjang.

Kaba Sabai Nan Aluih menceritakan perselisihan antara dua raja, Raja Babandiang dan Raja Nan Panjang. Ini bermula saat Raja Nan Panjang ingin melamar Sabai Nan Aluih, putri Rajo Babandiang. Rajo Babandiang menolak keinginan Raja Nan Panjang dan menyebabkan ia murka kepada Raja Babandiang Tagak. Raja Nan Panjang mengajak Raja Babandiang untuk berkelahi. Dalam perkelahian itu, Raja Babandiang tewas ditembak oleh 
anak buahnya Raja Nan Panjang. Tidak terima dengan kematian ayahnya, Sabai pun menuntut balas dan akhirnya Raja Nan Panjangpun mati ditembak oleh Sabai Nan Aluih

Dalam kaba Sabai Nan Aluih terdapat beragam karakter yang ditemukan dalam setiap tokohnya. Karakter-karakter positif diperoleh dari beberapa tokoh utama, yaitu Raja Babandiang Tagak, Sadun Saribai dan Sabai ndan Aluih. Tokoh Raja Nan Panjang memiliki karakter yang bijaksana, bertanggung jawab, religious, tegas, berani, jujur, mandiri, penyayang, Cinta damai dan Pekerja keras. Tokoh Sadun Saribai memiliki karakter yang dermawan, peduli sosial, komunikatif, rela berkorban dan sabar. Tokoh Sabai Nan Aluih memilki karakter bijaksana, tegas, sopan, penyayang, mandiri, berani, rela berkorban, sabar dan komunikatif. Sedangkan karakter negatif diperoleh dari penokohan Raja Nan Panjang. Karakter-karakter negatif tersebut terdiri dari Serakah, Sombong dan Kejam.

Beragam karakter yang ditemukan dalam dalam Kaba Sabai Nan Aluih, baik itu karakter positif maupun karakter negatif diharapkan dapat memperkaya dan menghidupkan kembali nilai-nilai budaya nusantara, khususnya budaya Minangkabau dalam penguatan pendidikan karakter yang dicanangkan oleh pemerintah dalam Perpres Nomor 87 Tahun 2017 tentang Penguatan Pendidikan Karakter.

Berdasarkan kajian teks yang sudah dilakukan, maka didapatkan hasil penelitian bahwa terdapat dua bentuk karakter dalam Kaba Sabai Nan Aluih, yaitu 16 Karakter positif dan 3 karakter negatif. Karakter positif tersebut terdiri dari karakter Religius, Tanggung Jawab, Peduli Sosial, Bijaksana, Kasih Sayang, Berani, Jujur, Cinta Damai, Kerja Keras, Mandiri, Dermawan, Komunikatif, Rela Berkorban, Sabar, Tegas dan Sopan. Sedangkan karakter negatif terdiri dari karakter Serakah, Sombong dan Kejam. Karakter-karakter yang ditemukan dalam Kaba Sabai Nan Aluih diharapkan dapat memperkaya dan merevitalisasi nilai-nilai budaya dalam pendidikan karakter.

Pendidikan karakter dapat diartikan sebagai segala upaya yang dapat dilakukan untuk mempengaruhi karakter siswa. Pendidikan karakter merupakan upaya sengaja untuk membantu seseorang agar dapat memahami, memperhatikan, dan menjalankan nilai-nilai inti etika. Berawal dari definisi tersebut, ketika kita memikirkan tentang jenis karakter yang ingin kita bangun pada diri siswa, jelas bahwa pada saat itu kita ingin mereka mampu memahami nilai-nilai tersebut, lebih memperhatikan nilai sebenarnya dari nilai-nilai tersebut, dan kemudian melakukan apa yang dia yakini, meskipun dia harus menghadapi tantangan dan tekanan baik dari luar maupun dari dalam dirinya (Lickona, 1991; Singh, 2019; Lickona, Schaps, Lewis, 2007; Lapsley, Narvaez, 2007). Pendidikan karakter harus 
diterapkan pada pemikiran individu mulai dari anak-anak, remaja bahkan orang dewasa, agar karakter individu lebih bernilai dan bermoral.

Berdasarkan temuan-temuan karakter dalam teks Kaba Sabai Nan Aluih diharapkan dapat memperkaya dan merevitalisasi nilai-nilai budaya dalam pendidikan karakter. Pendidikan karakter harus diterapkan pada pemikiran individu mulai dari anak-anak, remaja bahkan orang dewasa, agar karakter individu lebih bernilai dan bermoral.

\section{KESIMPULAN}

Berdasarkan kajian teks Kaba Sabai Nan Aluih yang sudah dilakukan, maka ditemukan dua bentuk karakter yaitu karakter positif sebanyak 16 karakter dan karakter negatif sebanyak 3 karakter. Karakter positif tersebut terdiri dari karakter Religius, Tanggung Jawab, Peduli Sosial, Bijaksana, Kasih Sayang, Berani, Jujur, Cinta Damai, Kerja Keras, Mandiri, Dermawan, Komunikatif, Rela Berkorban, Sabar, Tegas dan Sopan. Sedangkan karakter negatif terdiri dari karakter Serakah, Sombong dan Kejam. Beragam Karakter yang sudah ditemukan dalam Kaba Sabai Nan Aluih diharapkan dapat memperkaya dan merevitalisasi nilai-nilai budaya dalam pendidikan karakter.

\section{DAFTAR RUJUKAN}

Abdurahman. (2011). Nilai-nilai Budaya dalam Kaba Minangkabau: Suatu Interpretasi Semiotik. UNP Press Padang.

Abu Bakar, K. A., Noor, I. H. M., \& Widodo. (2018). Nurturing nationalism character valuesat the primary schools in jayapura, papua. Cakrawala Pendidikan, 37(1), 4256. https://doi.org/10.21831/cp.v37i1.13616

Almos, R., Pramono, \& Reniwati. (2014). Pantun dan Pepatah-Petitih Minangkabau Berleksikon Flora dan Fauna. Adabiyyat: Jurnal Bahasa Dan Sastra, 13(2).

Batubara, J. R. (2010). Adolescent Development (Perkembangan Remaja). Jurnal Sari Pediatri, 12(1).

David R. Shaffer, \& Kipp, K. (2010). Developmental Psychology: Childhood and Adolescence (Eighth Edition). USA: Wadsworth.

Djamaris, E. (1992). Kaba Rambun Pamenan. Departemen Pendidikan dan Kebudayaan.

Harahap, A., \& Hasibuan, A. (2018). Model of Prevention of Social Conflict which Multi Dimensions Based on Local Wisdom of Community Adat Dalihan Na Tolu. Brawijaya Law Journal, $2(2), \quad 159-172$. https://doi.org/10.21776/ub.blj.2018.005.02.01

Hayati, R. (2019). Implementasi Pendidikan Karakter Cerdas Format Klasikal (PKC-KA) Dalam Layanan Informasi. Al-Irsyad, 9(1), 89-101.

Hazen, E., Schlozman, S., \& Beresin, E. (2008). Adolescent psychological development: A review. Pediatrics in Review, 29(5), 161-168. https://doi.org/10.1542/pir.29-5-161

Idrus, M. (2012). Pendidikan Karakter Pada Keluarga Jawa. Jurnal Pendidikan Karakter, II(2), 118-130. https://doi.org/10.21831/jpk.v0i2.1297 
Lerner, R. M., \& Laurence, S. (2004). Handbook of adolescent psychology (Second Edition). New Jersey: John Wiley \& Sons, Inc.

Lickona, T. (1991). Educating for Character, How Our Schools Can Teach Respect and Responsibility. New York: Bantam Books.

Mappiare-AT, A. (2013). Tipe-tipe Metode Riset Kualitatif: untuk Eksplanasi Sosial, Budaya dan Bimbingan Konseling. Malang: Elang Mas.

Maunah, B. (2016). Implementasi Pendidikan Karakter Dalam Pembentukan Kepribadian Holistik Siswa. Jurnal Pendidikan Karakter, (1), 90-101. https://doi.org/10.21831/jpk.v0i1.8615

Miftah, M. (2016). Multicultural Education in the Diversity of National Cultures. QIJIS (Qudus International Journal of Islamic Studies), 4(2), 167. https://doi.org/10.21043/qijis.v4i2.1766

Murdiono, M., Miftahuddin, \& Kuncorowati, P. W. (2017). The Education of the National Character of Pancasila in Secondary School Based on Pesantren. Cakrawala Pendidikan, (3), 423-434. https://doi.org/https://doi.org/10.21831/cp.v36i3.15399

Pala, A. (2011). The Need For Character Education. International Journal Of Social Sciences And Humanity Studies, 3(2).

Penghulu, M. R. M. D. R. (2008). Kaba Sabai Nan Aluih. Bukittinggi: Kristal Multimedia.

Piliang, E., \& Sungut, N. D. M. (2018). Tambo Minangkabau: Budaya dan Hukum Adat Di Minangkabau. Bukittinggi: Kristal Multimedia.

Pradhan, R. K. (2009). Character, Personality and Professionalism. Social Science International., 25(2).

Setiawan, D. (2013). Peran Pendidikan Karakter Dalam Mengembangkan Kecerdasan Moral. Jurnal Pendidikan Karakter, III(1), 53-63. https://doi.org/10.21831/jpk.v0i1.1287

Siswati, Utomo, C. B., \& Muntholib, A. (2018). Implementasi Pendidikan Karakte Dalam Membentuk Sikap dan Perilaku Peserta Didik Melalui Pembelajaran Sejarah di SMA PGRI 1 Pati Tahun Pelajaran 2017/2018. 6(1), 1-13.

Sudrajat, A. (2011). Mengapa Pendidikan Karakter. Jurnal Pendidikan Karakter, 1(1), 4758. https://doi.org/10.21831/jpk.v1i1.1316

Ubaidillah, A. F., Bafadal, I., Ulfatin, N., \& Supriyanto, A. (2020). Cultivating marine leadership character through multicultural boarding-school system. Cakrawala Pendidikan, 39(1), 191-206. https://doi.org/10.21831/cp.v39i1.28344

Wardah, F., Hastuti, D., \& Krisnatuti, D. (2019). Pengaruh Metode Sosialisasi Orang Tua Dan Kontrol Diri Terhadap Karakter Sopan Santun Remaja. Jurnal Pendidikan Karakter, $I X(2)$.

Zainuddin, M. (2014). Ranah Minang dan Lingkungan Hidup. Yogyakarta: Ombak.

Zubaidah. (2019). Telaah Nilai Pepatah Minangkabau Sasek Di Ujuang Jalan Suruik Ka Pangka Jalan dan Kontribusinya Dalam Konseling Budaya. AlFuad Journal, 3(1), 4151. 